AMARAL, J.B.S. et al. Caracterização bromatológica e perfil em ácidos graxos de bebidas lácteas não-fermentadas. PUBVET, Londrina, V. 6, N. 7, Ed. 194, Art. 1302, 2012.

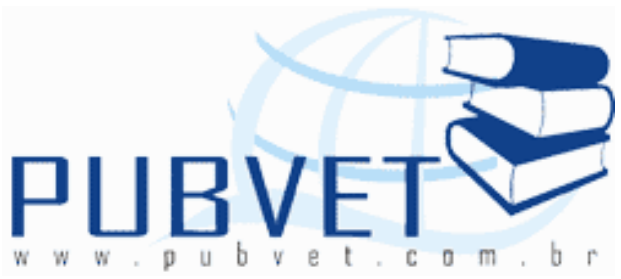

PUBVET, Publicações em Medicina Veterinária e Zootecnia.

\title{
Caracterização bromatológica e perfil em ácidos graxos de bebidas lácteas não-fermentadas
}

\section{João Batista Silvestre do Amaral $^{1}$, Denise Maria Pinheiro ${ }^{2}$, Johnnatan Duarte de} Freitas $^{3}$, Edma Carvalho de Miranda ${ }^{2}$, Cyro Rego Cabral Júnior ${ }^{4} *$

${ }^{1}$ Professor M.Sc. - Instituto Federal de Alagoas - Campus Maceió

${ }^{2}$ Profa. Dra. - Instituto de Química e Biotecnologia / Universidade Federal de Alagoas

${ }^{3}$ Prof. Dr. - Instituto Federal de Alagoas - Campus Maceió

${ }^{4}$ Prof. Dr. - Faculdade de Nutrição / Universidade Federal de Alagoas. Campus A. C. Simões, Km 14, Tabuleiro dos Martins, 57072-970 - Maceió, AL - Brasil. E-mail: cyrorcjr@gmail.com

\section{Resumo}

O principal objetivo deste trabalho é determinar o conteúdo em ácidos graxos de bebidas lácteas não fermentadas disponíveis no comércio da cidade de Maceió-AL. Amostras de bebidas lácteas não fermentadas obtidas no comércio de Maceió foram submetidas a análises de $\mathrm{pH}$, lipídios, carboidratos, proteínas e o conteúdo em ácidos graxos por cromatografia gasosa de seus ésteres metílicos. As amostras apresentaram nas informações nutricionais da embalagem, em valores médios, teor de gorduras trans nulo, teor de proteínas de $4,3 \mathrm{~g} / 200 \mathrm{~mL}$, lipídios totais de $4,9 \mathrm{~g} / 200 \mathrm{~mL}$ e carboidratos de $30,5 \mathrm{~g} / 200$ $\mathrm{mL}$. Os resultados analíticos mostraram que o $\mathrm{pH}$ das amostras esteve entre 
AMARAL, J.B.S. et al. Caracterização bromatológica e perfil em ácidos graxos de bebidas lácteas não-fermentadas. PUBVET, Londrina, V. 6, N. 7, Ed. 194, Art. 1302, 2012.

6,6 e 7,0; o teor de carboidratos totais entre 14,1 e $24,9 \mathrm{~g} / 200 \mathrm{~mL}$; o teor de lipídios totais variou de 3,7 a $6,3 \mathrm{~g} / 200 \mathrm{~mL}$; o teor de proteínas de 2,5 a 4,9 $\mathrm{g} / 200 \mathrm{~mL}$. A análise cromatográfica mostrou que os ácidos graxos mais abundantes foram C6:0, C8:0, C10:0, C11:0, C12:0, C14:0, C15:0, C16:1n7c, $\mathrm{C} 16: 0, \mathrm{C} 18: 2 \mathrm{n} 6 \mathrm{c}, \mathrm{C} 18: 2 \mathrm{n} 6 \mathrm{t}, \mathrm{C} 18: 1 \mathrm{n} 9 \mathrm{c}+\mathrm{C} 18: 1 \mathrm{n} 9 \mathrm{t}, \mathrm{C} 18: 0 . \mathrm{Os}$ resultados analíticos divergem das informações nas embalagens, o teor de gordura trans não é nulo, e o composto alimentar apresenta ácidos graxos essenciais ômega 6, mas nenhum ômega 3 .

Termos de Indexação: bebida láctea, conteúdo em ácidos graxos, GC-MS

\title{
Bromatologic characterization and fat acids profile in not fermented milk beverages
}

\begin{abstract}
The main objective of this work is to determine the fat acids profile of milk beverages not fermented available in the market of Maceió-AL city. Samples of milk beverage not fermented were acquired in Maceio's market and it were submitted for $\mathrm{pH}$, lipids, protein, and fat acids content by gas chromatographic GC-MS analysis of its methyl esters. The samples shows in the package's nutritional information, in medium values, null trans fat contents, the contents of proteins of $4,3 \mathrm{~g} / 200 \mathrm{~mL}$, total lipids of $4,9 \mathrm{~g} / 200 \mathrm{~mL}$ and carbohydrates of $30,5 \mathrm{~g} / 200 \mathrm{~mL}$. The analytic results show that samples $\mathrm{pH}$ was between 6,6 and 7,0 ; the total carbohydrates content between 14,1 and $24,9 \mathrm{~g} / 200 \mathrm{~mL}$; the total lipids content changes about 3,7 and $6,3 \mathrm{~g} / 200 \mathrm{~mL}$; the proteins content on the range of 2,5 up to $4,9 \mathrm{~g} / 200 \mathrm{~mL}$. The chromatographic analysis shows that more abundant fat acids were C6:0, C8:0, C10:0, C11:0, C12:0, C14:0, C15:0, C16:1n7c, C16:0, C18:2n6c, C18:2n6t, C18:1n9c + C18:1n9t, C18:0. The analytical results disagree from package's nutritional information. The trans fat content was not null, and that food compound presented omega6 , but no omega-3 essentials fat acids.
\end{abstract}

Keywords: Milk beverage, fat acids profile, GC-MS 
AMARAL, J.B.S. et al. Caracterização bromatológica e perfil em ácidos graxos de bebidas lácteas não-fermentadas. PUBVET, Londrina, V. 6, N. 7, Ed. 194, Art. 1302, 2012.

\section{INTRODUÇÃO}

O conteúdo em ácidos graxos dos alimentos consiste no elenco dos ácidos graxos presentes em suas respectivas concentrações. A importância destas substâncias se deve a sua participação na construção dos atributos sensoriais dos alimentos, acrescentando valor calórico e nutricional aos mesmos e, ainda, ao fato de serem precursores de importantes metabólitos do organismo humano, podendo causar benefícios ou malefícios á saúde humana.

Os ácidos graxos poliinsaturados da família $\omega-3$ e $\omega-6$ são os precursores de substâncias com atividades fisiológicas e farmacológicas denominadas eicosanóides, que abrangem as tromboxanas, prostaglandinas, prostaciclinas e os leucotrienos (TURATTI et al., 2002). O equilíbrio entre a produção de prostaglandinas e tromboxanas inibe 0 aparecimento de doenças cardiovasculares. Adicionalmente, os ácidos graxos $\omega-3$ mostram efeito benéfico na prevenção de vários tipos de câncer (CURI et al., 2002). Os ácidos graxos $\omega-6$, por sua vez, exercem importante papel fisiológico como potentes mediadores da inflamação e efeito benéfico sobre o sistema imune (POMPÉIA et al., 1999).

Por várias décadas, o teor de colesterol dos alimentos tem sido de interesse nutricional, devido a uma possível conexão com aterosclerose e doença cardiovascular. Hoje, o papel do colesterol da dieta é controverso e maior atenção é dada aos níveis de colesterol sérico HDL-c e LDL-c que, entre outros, dependem da composição de ácidos graxos dos lipídios da dieta (GRUNDY, 1990).

Os ácidos graxos trans foram, recentemente, incluídos entre os lipídios dietéticos que atuam como fatores de risco para doença arterial coronariana, modulando a síntese do colesterol e suas frações e atuando sobre os eicosanóides (WORLD HEALTH ORGANIZATION - WHO, 1995; DIETSCHY, 1997). Esses ácidos estão presentes naturalmente em gorduras originadas de animais ruminantes (OKONEK, 1996) e em produtos alimentícios 
AMARAL, J.B.S. et al. Caracterização bromatológica e perfil em ácidos graxos de bebidas lácteas não-fermentadas. PUBVET, Londrina, V. 6, N. 7, Ed. 194, Art. 1302, 2012.

manufaturados, como margarinas e gordura vegetal hidrogenada, entre outros.

A diferença entre os ácidos graxos trans provenientes de gordura láctea e os de gordura hidrogenada não se refere apenas às quantidades, reduzidas na primeira e elevadas na segunda, mas, também, está relacionada ao tipo de isômero predominante em uma e em outra fonte. Entre os ácidos graxos trans resultantes do processo de bioidrogenação há o predomínio do ácido vacênico, enquanto na gordura que sofre hidrogenação prevalece o ácido elaídico.

O ácido elaídico é considerado como o principal competidor do linoléico no metabolismo humano, principalmente quando a ingestão deste é reduzida (BOLTON et al., 1995). Sugere-se que dietas ricas em competidores de ácidos graxos essenciais podem gerar mudanças na produção e formação de prostaglandinas e tromboxanos, os quais têm como precursores os ácidos graxos polinsaturados linoléico e alfa-linolênico (JONES et al., 2000). Além disso, a ação competitiva dos ácidos graxos trans com os polinsaturados pode se refletir sobre a redução do número de receptores de lipoproteínas de baixa densidade (LDL-C), contribuindo para a elevação de seus níveis plasmáticos (INTERNATIONAL LIFE SCIENCE INSTITUTE, 1995).

Embora desde 1995 a Organização Mundial da Saúde venha recomendando a ingestão moderada deste tipo de gordura na prevenção e no tratamento de doenças coronarianas, até o presente, são desconhecidos os teores de ácidos graxos trans nos alimentos industrializados (BRASIL MS/SVSPort. no 521-17/10/97). Em 1999, a Food and Drug Administration (FDA) sugeriu que a quantidade de ácidos graxos trans fosse incluída em rótulos de produtos, recomendando, quando computada como gorduras saturadas, a demarcação por símbolo informativo da quantidade específica de ácidos graxos trans (FDA, 1999).

Entende-se por bebida láctea o produto obtido a partir de leite ou leite reconstituído e/ou derivados de leite, reconstituídos ou não, fermentado ou não, com ou sem adição de outros ingredientes, onde a base láctea represente 
AMARAL, J.B.S. et al. Caracterização bromatológica e perfil em ácidos graxos de bebidas lácteas não-fermentadas. PUBVET, Londrina, V. 6, N. 7, Ed. 194, Art. 1302, 2012.

pelo menos $51 \%(\mathrm{~m} / \mathrm{m})$ do total de ingredientes do produto (MAA / SDA - IN $38-31 / 10 / 2000)$.

A classificação bebida láctea não fermentada refere-se ao produto não adicionado de cultivos de microrganismos ou de produtos lácteos fermentados, submetido a tratamento térmico adequado, mantendo como característica físico-química fundamental o teor mínimo de proteínas de origem láctea de 1,2 g/100g (MAA/DAS IN 38, 2000).

Entre os Ingredientes não lácteos adicionados (isoladamente ou em combinação) encontram-se glicídios, maltodextrina, pedaços/polpa/suco e outros preparados à base de frutas, mel, cereais, vegetais, gorduras vegetais, chocolate, café, especiarias, amidos ou amidos modificados, gelatina ou outros ingredientes alimentícios (MAA/DAS IN 38, 2000).

Em Maceió existem pelo menos 16 marcas de bebidas lácteas nãofermentadas disponíveis à venda, em diversos estabelecimentos comerciais, de pequeno e de grande porte, sendo a maior parte delas oferecidas no sabor chocolate e uma pequena parte em outros sabores, como o morango, em embalagens de $1.000 \mathrm{~mL}$ e de $200 \mathrm{~mL}$. Todas elas apresentam em suas informações nutricionais, impressas na embalagem, o teor de gorduras saturadas, insaturadas e trans, estas sempre com valor nulo.

O objetivo deste trabalho é determinar o conteúdo em ácidos graxos de bebidas lácteas não fermentadas, disponíveis no comércio de Maceió - AL.

\section{MATERIAL E MÉTODOS}

\subsection{Coletas das amostras de bebidas lácteas}

As amostras de bebidas lácteas UHT, de sabor chocolate, foram adquiridas em estabelecimentos comerciais da cidade de Maceió-AL, aleatoriamente, após levantamento em redes de supermercados de pequeno, médio e grande porte, de diferentes marcas, no período de 02/2009 a 12/2009. Foram coletadas três amostras, em embalagens de $1.000 \mathrm{~mL}$, de um mesmo lote, de cada marca. Após o registro dos dados de coleta, as amostras foram conduzidas ao Laboratório de Química do Instituto Federal de Alagoas (IFAL). 
AMARAL, J.B.S. et al. Caracterização bromatológica e perfil em ácidos graxos de bebidas lácteas não-fermentadas. PUBVET, Londrina, V. 6, N. 7, Ed. 194, Art. 1302, 2012.

\subsection{Tratamento das amostras}

As amostras, em triplicata, de mesma marca e mesmo lote (Quadro 1), foram submetidas às análises, em triplicata, no Laboratório de Química do Instituto Federal de Alagoas (IFAL) e/ou no Laboratório de Enzimologia e Análises Bromatológicas, do Instituto de Química e Biotecnologia, da Universidade Federal de Alagoas (UFAL).

Quadro 1. Codificação das Amostras

\begin{tabular}{l|l}
\hline CODIGO & Produto \\
\hline BL1 $A, B, C)$ & $\begin{array}{l}\text { Leite UHT Aromatizado Semidesnatado Sabor Chocolate } \\
\text { Vitaminado }\end{array}$ \\
\hline BL2 (A, B, C) & $\begin{array}{l}\text { Bebida Láctea Esterilizada Sabor Chocolate -Leite } \\
\text { Achocolatado }\end{array}$ \\
\hline BL3 $(A, B, C)$ & Composto Alimentar Sabor Chocolate \\
\hline BL4 (A, B, C) & Bebida Láctea UHT Sabor Chocolate \\
\hline BL5 (A, B, C) & Bebida Láctea UHT Sabor Chocolate \\
\hline BL6 (A, B, C) & Bebida Láctea UHT Sabor Chocolate \\
\hline BL7 (A, B, C) & Bebida Láctea UHT Sabor Chocolate \\
\hline BL8 (A, B, C) & Bebida Láctea UHT Sabor Chocolate \\
\hline BL9 (A, B, C) & Bebida Láctea UHT Sabor Chocolate \\
\hline BL10 (A, B, & $\begin{array}{l}\text { Composto Alimentar Sabor Chocolate enriquecido com } \\
\text { C) }\end{array}$ \\
\hline
\end{tabular}

Todas as amostras foram conservadas sob refrigeração durante a realização das análises e desenvolvimento da pesquisa.

As amostras foram inspecionadas quanto ao estado de conservação da embalagem, condições de armazenamento (local, temperatura, iluminação, ventilação e umidade do ambiente), prazo de validade e informações nutricionais dos rótulos. As informações Nutricionais das Embalagens foram registradas e aquelas que apresentam relevância para este estudo estão transcritas na Tabela 1. 
AMARAL, J.B.S. et al. Caracterização bromatológica e perfil em ácidos graxos de bebidas lácteas não-fermentadas. PUBVET, Londrina, V. 6, N. 7, Ed. 194, Art. 1302, 2012.

Tabela 1. Informações Nutricionais do Rótulo das amostras de bebidas lácteas não fermentadas, em maio/2010, Maceió-AL

\begin{tabular}{cccccc}
\hline Amostra & $\begin{array}{c}\text { Carboidratos } \\
\mathrm{g} / 200 \mathrm{~mL}\end{array}$ & $\begin{array}{c}\text { Proteínas } \\
\mathrm{g} / 200 \mathrm{~mL}\end{array}$ & $\begin{array}{c}\text { Gorduras } \\
\text { totais } \\
\mathrm{g} / 200 \mathrm{~mL}\end{array}$ & $\begin{array}{c}\text { Gorduras } \\
\text { saturadas } \\
\mathrm{g} / 200 \mathrm{~mL}\end{array}$ & $\begin{array}{c}\text { Gorduras } \\
\text { trans } \\
\mathrm{g} / 200 \mathrm{~mL}\end{array}$ \\
\hline BL1 & 31 & 6,0 & 7,0 & 2,0 & 0,0 \\
BL2 & 31 & 6,0 & 7,0 & 2,0 & 0,0 \\
BL3 & 32 & 3,9 & 4,7 & 2,1 & 0,0 \\
BL4 & 30 & 3,9 & 6,4 & 3,7 & 0,0 \\
BL5 & 32 & 3,8 & 3,0 & 1,9 & 0,0 \\
BL6 & 28 & 5,8 & 5,2 & 2,5 & 0,0 \\
BL7 & 31 & 3,4 & 4,0 & 1,4 & 0,0 \\
BL8 & 29 & 3,0 & 3,0 & 2,0 & 0,0 \\
BL9 & 29 & 3,1 & 4,5 & 1,6 & 0,0 \\
BL10 & 32 & 3,9 & 4,7 & 2,1 & 0,0 \\
\hline
\end{tabular}

\subsection{Determinação de Proteína}

As amostras foram analisadas quanto ao teor de proteína, segundo o método de Kjeldahl, que consiste na determinação do nitrogênio total, utilizando $0,1 \mathrm{~mL}$ de cada sub-amostra. $O$ fator utilizado para a obtenção do teor de proteína bruta foi 6,25, de acordo com as normas da AOAC (1990).

\subsection{Determinação de Lipídeos totais}

A determinação de lipídios totais foi realizada para todas as amostras em três etapas de acordo com o método a frio de Folch (FOLCH et al., 1957). A primeira etapa consiste na extração dos lipídios com clorofórmio:metanol (2:1), seguida da lavagem do extrato com solução de $\mathrm{NaCl}(0,58 \%)$, e por fim, o solvente foi recolhido através de rota-evaporação e o resíduo seco em estufa a $105^{\circ} \mathrm{C}$.

\subsection{Determinação do conteúdo de ácidos graxos}

A fração lipídica, obtida segundo o método de Folch, foi submetida à metilação dos seus ácidos graxos, segundo Hartman e Lago (1973), visando à 
AMARAL, J.B.S. et al. Caracterização bromatológica e perfil em ácidos graxos de bebidas lácteas não-fermentadas. PUBVET, Londrina, V. 6, N. 7, Ed. 194, Art. 1302, 2012.

determinação da composição dos ácidos graxos por cromatografia gasosa. Para a identificação dos ácidos graxos foi utilizada como padrão uma mistura de ésteres metílicos de ácidos graxos (Supelco: 18919-1AMP), comparando-se o tempo de retenção dos ésteres metílicos das amostras e dos padrões. A quantificação dos ácidos graxos foi efetuada expressando-se o resultado em $\mathrm{mg} / \mathrm{mL}$, com base no conteúdo da mistura padrão de ácidos graxos. Os extratos lipídicos esterificados foram injetados em cromatógrafo gasoso (Shimadzu, CG37-MS), no Laboratório de Química do IF-AL ou no Laboratório de Fitoquímica do Instituto de Química e Biotecnologia da UFAL, com a coluna SPB-5 $(30 \mathrm{~m} \times 0,25 \mathrm{~mm} \times 0,25 \mu \mathrm{m})$, com temperatura de injeção de $250^{\circ} \mathrm{C}$, temperatura de interface de $310^{\circ} \mathrm{C}$, temperatura da coluna $50^{\circ} \mathrm{C}(2 \mathrm{~min}$.$) ,$ $4^{\circ} \mathrm{C} / \mathrm{min}$ por $62 \mathrm{~min}$. e $250^{\circ} \mathrm{C} / 15 \mathrm{~min}$.; Split de $1: 31$, volume de injeção de $1 \mu \mathrm{L}$, utilizando como gás de arraste $\mathrm{H}_{2}$.

\subsection{Determinação de Carboidratos}

Os carboidratos das amostras foram hidrolisados através da adição de $\mathrm{HCl}$ (1N) sob aquecimento de $105^{\circ} \mathrm{C} / 5 \mathrm{~min}$., sendo quantificados através do método do ácido 3,5-dinitro-salicílico (DNS). Para isso, utilizou-se $0,5 \mathrm{~mL}$ de amostra e adicionou-se 0,5 do reagente de DNS; em seguida, os tubos foram colocados em banho com água a $100^{\circ} \mathrm{C}$ por 5 minutos. Após o resfriamento, foram adicionados $5 \mathrm{~mL}$ de água destilada e os tubos foram lidos em espectrofotômetro a 540nm.

\subsection{Determinação de pH}

A determinação de $\mathrm{pH}$ foi realizada em pHmetro de bancada, com uma casa decimal e correção automática do efeito da temperatura, após aferição do aparelho com soluções tampão de pH 4 e pH 7 e enxaguamento do eletrodo com água destilada entre as determinações, para todas as amostras. 
AMARAL, J.B.S. et al. Caracterização bromatológica e perfil em ácidos graxos de bebidas lácteas não-fermentadas. PUBVET, Londrina, V. 6, N. 7, Ed. 194, Art. 1302, 2012.

\section{RESULTADOS E DISCUSSÃO}

\subsection{Análises bromatológicas}

As bebidas lácteas estudadas neste trabalho apresentaram em suas formulações, conforme as informações registradas em seus rótulos: leite desnatado fluido e/ou reconstituído, leite em pó desnatado ou integral, soro de leite reconstituído, creme de leite ou gordura vegetal, cacau em pó, amido modificado, maltodextrina, açúcar, água, minerais e aditivos, ingredientes que contribuem em maior ou menor proporção com suas propriedades físicoquímicas e nutricionais para a qualidade do produto.

De acordo coma Tabela 2 pode-se verificar que as amostras tiveram o pH próximo à neutralidade e em valores esperados para leite $(6,4-6,6)$ exceto as amostras, BL2, BL4, e BL10 que apresentaram pH acima de 6,6 e as amostras BL3, BL7 e BL8 com valores abaixo de 6,4, com indicação de alguma alteração do produto, uma vez que alterações no $\mathrm{pH}$ de bebidas lácteas podem indicar proliferação de bactérias lácticas quando ocorre um abaixamento do $\mathrm{pH}$ ou falha operacional no processo de produção durante o ajuste do $\mathrm{pH}$ final da bebida, quando ocorre elevação do $\mathrm{pH}$ a valores acima da faixa indicada.

Segundo Eduardo e Lannes (2004), o pH de achocolatados depende do grau de alcalinização que o cacau apresenta e da quantidade de acidez do soro de leite utilizado; em geral, a indústria leva a um pH em torno de 7,0. Segundo esses autores, o pH do soro de leite pode variar de 6,5 a 6,7 e o de achocolatados de diversas marcas, variou 6,81 e 8,12.

As variações no $\mathrm{pH}$ podem ser consideradas como indício de alteração do produto, uma vez que podem indicar proliferação de bactérias (CURI et al., 2002). Caso o leite não seja tratado termicamente de forma adequada, ocorre o desenvolvimento de microrganismos, como o Staphylococcus aureus, que libera lipases, provocando a rancidez hidrolítica em produtos derivados, levando, assim, ao aumento na acidez do produto e ao conseqüente 
AMARAL, J.B.S. et al. Caracterização bromatológica e perfil em ácidos graxos de bebidas lácteas não-fermentadas. PUBVET, Londrina, V. 6, N. 7, Ed. 194, Art. 1302, 2012.

abaixamento do pH. Falhas operacionais no processo de produção durante o ajuste do pH final da bebida láctea são causas prováveis da elevação do $\mathrm{pH}$ a valores acima da faixa indicada.

Tabela 2. Valores médios de bebidas lácteas não fermentadas, em maio/2010, Maceió-AL

\begin{tabular}{c|c|c|c|c}
\hline Amostras & $\mathrm{pH}$ & $\begin{array}{c}\text { Carboidratos } \\
(\mathrm{g} / 200 \mathrm{~mL})\end{array}$ & $\begin{array}{c}\text { Lipídios } \\
(\mathrm{g} / 200 \mathrm{~mL})\end{array}$ & $\begin{array}{c}\text { Proteínas } \\
(\mathrm{g} / 200 \mathrm{~mL})\end{array}$ \\
\hline BL1 & $6,6 \pm 0,1 *$ & $22,9 \pm 4,9$ & $4,1 \pm 0,5$ & $2,5 \pm 0,1$ \\
BL2 & $6,7 \pm 0,0$ & $24,9 \pm 1,7$ & $4,9 \pm 1,1$ & $3,5 \pm 0,1$ \\
BL3 & $6,3 \pm 0,0$ & $21,1 \pm 0,2$ & $6,3 \pm 0,5$ & $3,9 \pm 0,3$ \\
BL4 & $7,0 \pm 0,1$ & $24,7 \pm 2,0$ & $6,4 \pm 2,0$ & $4,0 \pm 0,2$ \\
BL5 & $6,5 \pm 0,1$ & $14,1 \pm 0,4$ & $3,7 \pm 0,8$ & $4,5 \pm 0,0$ \\
BL6 & $6,5 \pm 0,0$ & $18,3 \pm 2,5$ & $5,3 \pm 0,5$ & $5,5 \pm 1,3$ \\
BL7 & $6,3 \pm 0,1$ & $22,4 \pm 4,7$ & $5,3 \pm 0,5$ & $4,7 \pm 0,2$ \\
BL8 & $6,3 \pm 0,0$ & $24,3 \pm 1,5$ & $5,6 \pm 0,1$ & $3,3 \pm 0,1$ \\
BL9 & $6,5 \pm 0,1$ & $24,1 \pm 0,4$ & $5,4 \pm 0,4$ & $3,1 \pm 0,1$ \\
BL10 & $6,7 \pm 0,0$ & $21,0 \pm 1,0$ & $4,1 \pm 0,4$ & $4,2 \pm 0,0$ \\
\hline
\end{tabular}

*Média \pm Desvio-Padrão.

Os carboidratos totais, expressos em g/200mL, apresentados na Tabela 2, encontram-se em valores inferiores aos indicados nas informações nutricionais, entre 28 e 32 g/200 mL (Tabela 1), atingindo discrepância maior nas amostras BL5 e BL6, indicando uma possível alteração na bebida láctea destas amostras. Por outro lado, o notável desvio sistemático entre os resultados obtidos e as informações nutricionais dos rótulos sugerem que 0 método analítico empregado neste trabalho é diverso do empregado na indústria.

Os carboidratos presentes nas bebidas lácteas são provenientes do leite e da sacarose, intencionalmente adicionada ao produto, substituída por edulcorantes e substitutos do açúcar nos produtos dietéticos. Os carboidratos 
AMARAL, J.B.S. et al. Caracterização bromatológica e perfil em ácidos graxos de bebidas lácteas não-fermentadas. PUBVET, Londrina, V. 6, N. 7, Ed. 194, Art. 1302, 2012.

totais expressos em $\mathrm{g} / 200 \mathrm{~mL}$, apresentados na Tabela 2, encontram-se em valores inferiores aos indicados nas informações nutricionais, entre 28 e 32 g/200 mL (Tabela 1), com discrepância maior nas amostras BL5 e BL6, indicando uma possível alteração nestas amostras.

Na Tabela 2 está apresentado o teor de lipídios totais (gorduras totais) das amostras, que variou de 3,7 a $6,4 \mathrm{~g} / 200 \mathrm{~mL}$, enquanto que os valores informados no rótulo variaram de 3 a $7 \mathrm{~g} / 200 \mathrm{~mL}$ (Tabela 1). Ainda que os valores individuais sejam divergentes, permanecem dentro da mesma faixa.

Segundo Molketin (2006), o teor de gordura no leite cru é de 3,93\% $(\mathrm{m} / \mathrm{m})(7,86 \mathrm{~g} / 200 \mathrm{~mL})$; a este deve ser acrescentado aquele oriundo do cacau ou de outras fontes usadas na formulação do produto lácteo. No estudo de Eduardo e Lannes (2004), o teor de lipídios em diversas marcas de achocolatados variou de 0,88 a 5,93 \% (aproximadamente 1,76 a 11,86 g/200 $\mathrm{mL}$ ), diferindo das informações veiculadas nos rótulos, que variou de 0,00 a $5,55 \%(\mathrm{~m} / \mathrm{m})$ (aproximadamente 0,00 a $11,10 \mathrm{~g} / 200 \mathrm{~mL}$ ). Estes valores mostram claramente que, muitas vezes, o que é veiculado no rótulo dos produtos difere da realidade, pois um teor de lipídios totais de zero é inexeqüível para estes produtos.

O teor de proteínas apresentado nas informações nutricionais variou de 3 a $6 \mathrm{~g} / 200 \mathrm{~mL}$ (Tabela 1) e se mostrou superior aos valores encontrados nas análises de caracterização (Tabela 2), com resultados entre 2,5 a 5,5 $\mathrm{g} / 200 \mathrm{~mL} \%$, com discrepâncias maiores para as amostras BL1 e BL2, que diferiram em 3,5 g/200 mL e 2,5 g/200 mL, respectivamente.

Eduardo e Lannes (2004) afirmam que a maior parte das proteínas dos achocolatados vem do leite e do soro de leite e que os achocolatados dietéticos apresentam o teor de proteínas maior devido à presença do aspartame, edulcorante aminado utilizado nestas formulações. Os autores encontraram variação no teor de proteínas, em diversas marcas de achocolatados, que variaram de 2,23 a 13,29 \%, divergindo das informações dos rótulos que indicavam uma variação de 12,6 a $13,29 \%$. 
AMARAL, J.B.S. et al. Caracterização bromatológica e perfil em ácidos graxos de bebidas lácteas não-fermentadas. PUBVET, Londrina, V. 6, N. 7, Ed. 194, Art. 1302, 2012.

\subsection{Análises Cromatográficas}

Os resultados obtidos para as bebidas lácteas quanto ao perfil qualitativo e quantitativo de ácidos graxos estão apresentados na Tabela 3.

Observou-se que em todas as bebidas lácteas analisadas foram encontrados teores de ácidos graxos trans (Linolelaidato de Metila (C18:2 n6t) e Oleato de Metila + Elaidato de Metila (C18:1 n9c + C18:1 n9t)), diferentemente do que fora informado nos rótulos dos produtos (Tabela 1).

Além disso, pode-se observar, ainda, que houve concentrações acima de $1 \mathrm{mg} / \mathrm{mL}$ de ácidos graxos saturados (Caproato de Metila (C6:0), Miristato de Metila (C14:0) e Estearato de Metila (C18:0)) e acima de $3 \mathrm{mg} / \mathrm{mL}$ para o Palmitato de Metila (C16:0). A composição em ácidos graxos mostrada na Tabela 3 ressalta que o AG que predominou em todas as amostras foi o ácido palmítico (C16:0), em concentrações que variaram de 2,66 a 6,21 mg/mL, seguido do ácido esteárico, na faixa de 0,64 a $2,42 \mathrm{mg} / \mathrm{mL}$. No entanto, foram notáveis, nas amostras BL2, BL3 e BL9, as elevadas concentrações de ácidos graxos trans (Oleato de Metila + Elaidato de Metila; C18:1 n9c + C18:1 n9t), $7,28,4,95,3,93 \mathrm{mg} / \mathrm{mL}$, respectivamente, comprovando a presença de AG trans neste produtos e contrariando as informações apresentadas nos rótulos.

As concentrações dos AG das amostras mostraram-se superiores para uns e inferiores para outros ácidos graxos presentes, em comparação com aqueles encontrados na literatura para o leite, como em Molketin (2006), que para amostras de leite in natura com teor de gordura de 3,93 \% encontrou a seguinte composição de ácidos graxos, em g/100g de gordura de leite bruto, C4: 3,36 ; C6: 2,2 ; C8: 1,31 ; C10: 2,97; C12: 3,6; C14: 10,48; C16: 30,85; C18: 9,33; C18:1 c/t /C18:2 c9,c12: 1,76; CLA (ácido oléico conjugado) C18:2 c9,t11: 0,47; C18:3 c9,c12, c15: 0,38. 
AMARAL, J.B.S. et al. Caracterização bromatológica e perfil em ácidos graxos de bebidas lácteas não-fermentadas. PUBVET, Londrina, V. 6, N. 7, Ed. 194, Art. 1302, 2012.

Tabela 3. Perfil em Ácidos Graxos de Bebidas Lácteas não-fermentadas ( $\mathrm{mg} / \mathrm{mL})$, em maio/2010,

\section{Maceió-AL}

\begin{tabular}{|c|c|c|c|c|c|c|c|c|c|c|c|c|}
\hline Pico & Ésteres Metílicos de Ácidos Graxos & Fórmula & $\mathrm{BL}-1$ & BL-2 & BL-3 & $\mathrm{BL}-4$ & BL-5 & BL-6 & BL-7 & BL-8 & BL-9 & $\mathrm{BL}-10$ \\
\hline 1 & Caproato de Metila & C6:0 & 1,10 & 0,60 & 0,75 & 1,43 & 1,40 & 0,42 & 1,19 & 0,81 & 0,00 & 1,20 \\
\hline 2 & Caprilato de Metila & C8:0 & 0,33 & 0,19 & 0,00 & 0,46 & 0,41 & 0,19 & 0,36 & 0,22 & 0,00 & 0,31 \\
\hline 3 & Caprato de Metila & C10:0 & 0,46 & 0,29 & 0,00 & 0,00 & 0,43 & 0,14 & 0,51 & 0,32 & 0,00 & 0,32 \\
\hline 4 & Undecanoato de Metila & C11:0 & 0,26 & 0,00 & 0,00 & 0,37 & 0,00 & 0,00 & 0,00 & 0,00 & 0,00 & 0,00 \\
\hline 5 & Laurato de Metila & C12:0 & 0,00 & 0,23 & 0,26 & 0,34 & 0,24 & 0,42 & 0,37 & 0,25 & 0,00 & 0,27 \\
\hline 8 & Miristato de Metila & C14:0 & 1,27 & 0,71 & 0,68 & 1,15 & 0,51 & 0,31 & 1,07 & 0,86 & 0,19 & 0,95 \\
\hline 10 & Pentadecanoato de Metila & C15:0 & 0,08 & 0,00 & 0,00 & 0,00 & 0,00 & 0,00 & 0,00 & 0,00 & 0,00 & 0,00 \\
\hline 11 & Palmitoleato de Metila & C16:1 n7c & 0,00 & 0,00 & 0,00 & 0,00 & 0,00 & 0,00 & 0,00 & 0,06 & 0,00 & 0,00 \\
\hline 12 & Palmitato de Metila & C16:0 & 5,35 & 4,72 & 3,76 & 6,21 & 2,66 & 5,75 & 6,10 & 5,78 & 3,21 & 5,62 \\
\hline 16 & Linoleato de Metila & C18:2 n6c & 0,00 & 0,00 & 1,42 & 0,13 & 0,00 & 1,35 & 0,00 & 0,11 & 2,84 & 0,00 \\
\hline 17 & Linolelaidato de Metila & $\mathrm{C} 18: 2 \mathrm{n} 6 \mathrm{t}$ & 0,25 & 0,22 & 0,33 & 0,23 & 0,11 & 0,46 & 0,26 & 0,33 & 0,35 & 0,29 \\
\hline 18 & Oleato de Metila + Elaidato de Metila & $\begin{array}{l}\text { C18:1 } \mathrm{n9c} \\
+\quad \mathrm{C} 18: 1 \\
\text { n9t }\end{array}$ & 1,08 & 7,28 & 4,95 & 0,00 & 0,00 & 0,00 & 1,14 & 1,30 & 3,93 & 0,00 \\
\hline 19 & Estearato de Metila & C18:0 & 1,80 & 2,33 & 1,53 & 1,42 & 0,64 & 0,98 & 1,41 & 1,72 & 2,42 & 2,03 \\
\hline
\end{tabular}


AMARAL, J.B.S. et al. Caracterização bromatológica e perfil em ácidos graxos de bebidas lácteas não-fermentadas. PUBVET, Londrina, V. 6, N. 7, Ed. 194, Art. 1302, 2012.

\section{CONSIDERAÇÕES FINAIS}

Neste trabalho, demonstrou-se que os valores de $\mathrm{pH}$, carboidratos, lipídios e proteínas informados nos rótulos diferem dos valores analisados através da caracterização e da determinação do perfil em ácidos graxos das bebidas lácteas não-fermentadas, comercializadas em Maceió-AL. Disponibilizam-se, assim, para profissionais da nutrição, indústrias e órgão governamentais informações valiosas para o aperfeiçoamento de produtos e serviços.

As amostras, BL2, BL4 e BL10, que apresentaram pH acima de 6,6, e as amostras BL3, BL7 e BL8, com valores abaixo de 6,4, têm indicação de alguma alteração do produto, uma vez que alterações no pH de bebidas lácteas podem indicar proliferação de bactérias lácticas, quando ocorre um abaixamento do $\mathrm{pH}$, ou falha operacional no processo de produção durante o ajuste do $\mathrm{pH}$ final da bebida, quando ocorre elevação do $\mathrm{pH}$ a valores acima da faixa indicada.

Nas amostras BL5 e BL6 houve diferenças no teor de carboidratos, indicando uma possível alteração na bebida láctea destas amostras; no entanto, o método de determinação de carboidratos totais utilizado neste trabalho pode ser diferente do empregado na indústria, o que poderia justificar as diferenças observadas. Tal suspeita, entretanto, não pôde ser confirmada, devido à falta de informação nas embalagens dos produtos.

O teor de proteínas das amostras mostrou que BL1 e BL2, 3,5 g/200 mL e $2,5 \mathrm{~g} / 200 \mathrm{~mL}$, respectivamente, se mostraram inferiores às informações nutricionais indicadas nos rótulos, 3 a $6 \mathrm{~g} / 200 \mathrm{~mL}$.

O teor de lipídios totais das amostras analisadas variou de 3,7 a $6,4 \mathrm{~g} / 200$ $\mathrm{mL}$, enquanto que os valores informados no rótulo variaram de 3 a $7 \mathrm{~g} / 200$ $\mathrm{mL}$. Mas, essa discrepância pode ser considerada normal uma vez que os valores individuais permanecem dentro da mesma faixa.

As amostras BL2, BL3 e BL9 apresentaram elevadas concentrações de ácidos graxos trans (Oleato de Metila + Elaidato de Metila; C18:1 n9c + C18:1 $\mathrm{n} 9 \mathrm{t}), 7,28,4,95,3,93 \mathrm{mg} / \mathrm{mL}$, respectivamente, comprovando a presença de AG trans nestas amostras de bebidas lácteas não fermentadas, contrariando as informações apresentadas nos rótulos e na propaganda dessas amostras. 


\section{REFERÊNCIAS}

1. ASSOCIATION OF OFFICIAL ANALYTICAL CHEMISTS, Washington, D. C. Official methods of analysis. 15 th ed., Washington, 1990. 109p.

2. BOLTON-SMITH, C.; WOODWARD, M.; FENTON, S.; MCCLUSKEY, M. K. and BROWN, C. A. Trans fatty acids in the Scottish diet - An assessment using a semi-quantitative foodfrequency questionnaire, British Journal of Nutrition (1995), 74, 661470

3. CURI, R.; POMPÉIA, C.; MIYASAKA, K.; PROCOPIO, J.; Entendendo as Gorduras - Os Ácidos Graxos. São Paulo, Editora Manole Ltda. $1^{\circ}$ ed., 2002.

4. DIETSCHY JM. Theoretical considerations of what regulates low-density-lipoprotein and high-density-lipoprotein cholesterol. American Journal of Clinical Nutrition 1997; 65 (5 Suppl):1581S-9S.

5. EDUARDO, Mércia de F.; LANNES, Suzana C. da S. Achocolatados: análise química, RBCFRevista Brasileira de Ciências Farmacêuticas (Brasilian Journal of Pharmaceutical Sciences) V.40, 3, jul./set./ 2004.

6. FOLCH, J. LEES, M., SLOANNE STANLEY, G. H. A simple method for the isolation and purification of total lipide from animal tissues. Journal of Biological Chemistry, Baltimore, 226: 497-509, 1957.

7. FOOD AND DRUG ADMINISTRATION. FDA proposes new rules for trans fatty acids in nutrition labeling, nutrient content clains, and health clains. [cited 1999 Out 29]. Available from: www.access.gpo. gov/su docs

8. GRUNDY, SM; DENSKE, MS. Dietary influences of serum lipids and lipoprotein, Journal of Lipid Research 1990 31:1149-1172.

9. HARTMAN, L.; LAGO, B. C. A. Rapid preparation of fatty methyl esters from lipids. Laboratory. Practice. v. 22, p. 475-477, 1973.

10. INTERNATIONAL LIFE SCIENCES INSTITUTE. Trans fatty acids and coronary heart disease risk. Report of the expert. Panel on trans fatty acids and coronary heart disease. American Journal of Clinical Nutrition 1995; 62(3 Suppl): 518-26.

11. JONES PJH, KUBOW S. Lipids, Sterols, and Their Metabolites. In: Shils ME. Modern nutrition in health and disease. Part A. Major Dietary Constituents and Energy Needs. 9th. Philadelphia: Lippincott Williams \& Wilkins; 2000. p.67-93.

12. MOLKETIN, Cholesterol content and lipid composition of low fat dairy products, European Food Research Technology (2006) 223: 253-260.

13. OKONEK DV, BERBEN PH, MARTELLI G. Precious metal catalysis for fats and oils applications. In: Anais do Seminário da Sociedade Brasileira de Óleos e Gorduras, 1996. Gorduras modificadas com baixos teores de ácidos graxos trans: aspectos nutricionais e tecnológicos. São Paulo: Instituto Adolfo Lutz; 1996. p.39-46.

14.POMPÉIA, C.; PROCÓPIO, J.; CURI, R. Fatty acids and the immune system. Revista Brasileira de Ciências Farmacêuticas (Brazilian Journal of Pharmaceutical Science), 35(2): 165-194., 1999.

15. PRECHT, D; Cholesterol content in European bovine milk fats, Nahrung/food 2001 45: 28.

16. TURATTI, J. M.; GOMES, R. A. R.; ATHIÉ, I. LIPÍDEOS: Aspectos funcionais e novas tendências. Campinas: ITAL, 2002. 78p. 
17. WORLD HEALTH ORGANIZATION. Nutrition. Science - Policy. WHO and FAO Joint Consultation: fats and oils in human nutrition. Nutrition Review 1995; 53(7): 202-5. 